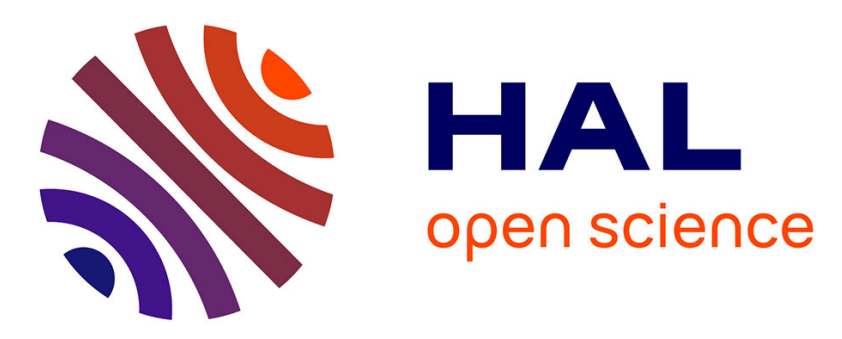

\title{
Clinical experience with cold plasma in the treatment of locally advanced head and neck cancer
}

\author{
Hans-Robert Metelmann, Christian Seebauer, Vandana Miller, Alexander \\ Fridman, Georg Bauer, David B Graves, Jean-Michel Pouvesle, Rico \\ Rutkowski, Matthias Schuster, Sander Bekeschus, et al.
}

\section{To cite this version:}

Hans-Robert Metelmann, Christian Seebauer, Vandana Miller, Alexander Fridman, Georg Bauer, et al. Clinical experience with cold plasma in the treatment of locally advanced head and neck cancer. Clinical Plasma Medicine, 2018, 9, pp.6. 10.1016/j.cpme.2017.09.001 . hal-01940492

\section{HAL Id: hal-01940492 \\ https://hal.science/hal-01940492}

Submitted on 4 Jan 2021

HAL is a multi-disciplinary open access archive for the deposit and dissemination of scientific research documents, whether they are published or not. The documents may come from teaching and research institutions in France or abroad, or from public or private research centers.
L'archive ouverte pluridisciplinaire HAL, est destinée au dépôt et à la diffusion de documents scientifiques de niveau recherche, publiés ou non, émanant des établissements d'enseignement et de recherche français ou étrangers, des laboratoires publics ou privés. 
Original research article

\section{Clinical experience with cold plasma in the treatment of locally advanced head and neck cancer}

Hans-Robert Metelmann ${ }^{a, m, *}$, Christian Seebauer ${ }^{a, h, m}$, Vandana Miller ${ }^{b}$, Alexander Fridman ${ }^{b}$, Georg Bauer ${ }^{c}$, David B. Graves ${ }^{\mathrm{d}}$, Jean-Michel Pouvesle ${ }^{e}$, Rico Rutkowski ${ }^{a}$, Matthias Schuster ${ }^{\mathrm{a}}$, Sander Bekeschus ${ }^{\mathrm{f}, \mathrm{h}, \mathrm{m}}$, Kristian Wende ${ }^{\mathrm{f}, \mathrm{h}, \mathrm{m}}$, Kai Masur ${ }^{\mathrm{f}, \mathrm{h}, \mathrm{m}}$, Sybille Hasse ${ }^{\mathrm{h}, \mathrm{m}}$, Torsten Gerling,h, Masaru Hori ${ }^{\mathrm{g}}$, Hiromasa Tanaka ${ }^{\mathrm{g}}$, Eun Ha Choi ${ }^{\mathrm{i}}$, Klaus-Dieter Weltmann ${ }^{\mathrm{h}, \mathrm{m}}$, Philine Henriette Metelmann ${ }^{\mathrm{a}, \mathrm{j}, \mathrm{m}}$, Daniel D. Von Hoff ${ }^{\mathrm{k}}$, Thomas von Woedtke ${ }^{\mathrm{h}, \mathrm{l}, \mathrm{m}}$

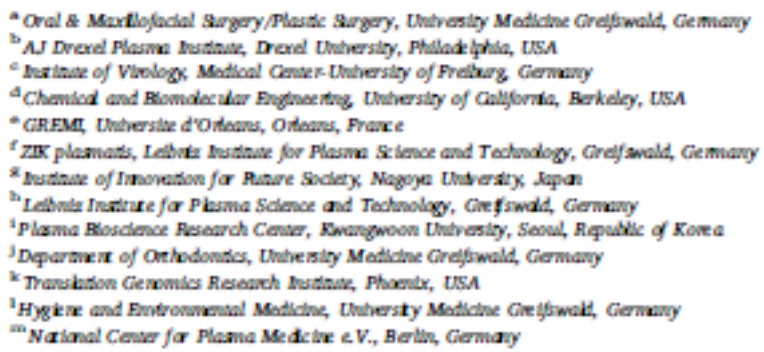

\section{A R T I C LE IN F O}

\section{Keymords}

CAP

Oropharyax cances

Imm unotherapy

Apoperaila

\section{A B S T R A C T}

Puppase Cold atmospheric pressure plesma (CAP) is well known for insctivating microbial pathogens and sti. mulation of tisue regeneration in chrunic wounds. Several authors have reparted the effectiveness against cancer in different $\mathbf{E l l}$ lines and animal models. This is the first report of patients with real dinical benefit following appliation of CAP, not just visible change of the tumor surface but hating partial remision. The authors discuss the CAP treatment approach and the efficacy for inoperable head and neck cancer patients. Methods: The trial enrolled six patients with bcally advanced (pT4) squamous cell arcinoma of the aropharyrax suffering frum open infocted ulcerations. Patients were treated with a jet plasma source (k.NPen MFD, neoplas tools GmbH, Greifswald, Gemany) in cycles of 3 single applications (1 min $/ \mathrm{cm}^{2}$ frum a distance of $\left.8 \mathrm{~mm}\right)$ within 1 week, each followed by an intennittence of 1 week.

Realts: CAP treatment resulted in a rechuction in odar and pain mecication requirements, in improvement in social function and a positive emotional affect. Further olwervance revealed partial remission in two patients far at least nine month hcisional biopsies at remission demonstrate a moderate amount of apoptotic tumor celk and a desmoplestic reaction of the connective tisure.

Canchicion: The trial demonstrates the clinical rekevana of CAP in ancer trea tment. There are three arporoaches for discussion of tumor remission: (i) the role of myeloid cells, (ii) the ROS/RONS model of cellular impact and (iii) the immunogenic cell death model of cancer treatment, and there is a reflection on nonsustainable tumor response due to adapted tumor microenvironment.

\section{Introduction}

The development of sources providing physical plasma at body temperature and under atmospheric pressure has opened the use of plasma components for medical purposes. From the clinical point of view the approval of the first plasma sources for medical treatment purposes in 2013 has been based upon their well-known effectiveness not only to stimulate tissue regeneration but also against microbial

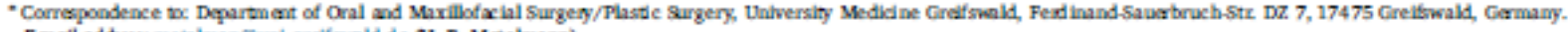

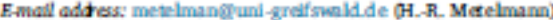

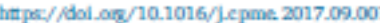

Recelved 11 July 2017; Rexdred in reviod form 19 September 2017; Axegted 20 September 2017 2212-81 66/ 82017 Elsevier CimbH. All rights reserved. 
pathogens. Cold atmospheric pressure plasma (CAP) has shown to be effective in cancer as well. Schlegel and coworkers in 2013 were the first to list the antitumor act ivity of CAP. The antitumor of effect of CAP has also been demonstrated in various types of cancer cell lines in vitro, such as melanoma, glioblastoma, lung cancer, colon cancer, pancreatic cancer, breast cancer, leukemia, thyroid cancer, and head and neck cancer. Several studies in experimental animal modek have underlined this notion using eg. melanoma, colon cancer, pancreatic cancer, endometrial adenocarcinoma, and ovarian cancer cells [1].

We have observed from our clinical experience that many patients with locally advanced squamous cell carcinoma of the oropharynx suffer severely from microbial contamination and odorous infection of their tumor ulcerations After approval of the CAP device we began bcal application of CAP for decontamination. Palliation therapy by CAP was effective in the reduction of thestrong fetid odor and pain [2]. En passart, application of CAP has been observed to cause visible changes of the tumo surface similar to small and bcal regression [3] that was not accompanied by serious side effects [4].

This paper is documenting and discussing six patients " clinical CAP treatment results in terms of survival time, course of disease, tumor remission and safety. The approved indication was antimicrobial control as part of a standard treatment protocol for palliation.

\section{Material and methods}

The protocol was designed as a prospective treatment observation (protocol H) including 6 patients $(\mathrm{H} 1-\mathrm{H} 6)$.

\subsection{Complance with ethical standards}

All procedures including assessing data from the patients were in accordance with the ethical standards of the institutional and national research committee and with the 1964 Helsinki declaration and its later amendments. All patients gave written informed consent before inclusion in the study.

\subsection{Patient recruitment}

Patients suffering from locally advanced cancer of the oropharynx (pT4) with contaminated tumor ulcerations and with no lasting remission following curative intended tumor treatment were offered CAP treatment (Table 1). Recruitment, treatment and follow-up of all patients were performed at the department of oral and maxilbfacial surgery, Greifswald University Medicine, between January 2015 and March 2017.

\section{3. hclusion, exclusion and dropout criteria}

Appropriate indications for CAP treatment were infected cancer ulcerations, easily and dependably accessible for CAP hand piece and jet stream. The linguistic, physical and mental ability to understand the nature of CAP treatment and to participate in the study was necessary. No special exclusion criteria despite the manufactures instructions were applied. Dropout criteria were the occurrence of undesired effects and aggravation of the microbial contamination.

\subsection{Therapy}

CAP was made applicable by a jet plasma source (kINPen MED, neoplas tools $\mathrm{GmbH}$, Greifswald, Germany), a medical device pre viously described in basic technical detail [5]. The device consists of a hand-held unit that discharges plasma under atmospheric conditions, requiring a DC power unit and Argon gas reservoir. In the center of a ceramic capillary (inner diameter $1.6 \mathrm{~mm}$ ) a pin-type electrode ( $1 \mathrm{~mm}$ diameter) is mounted. The needle is powered by a miniaturized RF generator producing a sinusoidal voltage waveform ranges from $2 \mathrm{kV}$ to $3 \mathrm{kV}$ amplitude peak at a frequency of $1 \mathrm{MHz}$ and modulated with $2.5 \mathrm{kHz}$ and a plasma duty cycle of $1: 1$.

The plasma is generated at the tip of the central electrode and expands into the surrounding air outside the nozzle. The system works with argon gas and flow rate of $5 \mathrm{sm}$. During operation, the length of the plasma jet (effluent) extends $10 \mathrm{~mm}$ from the ceramic capillary. Under these conditions, the maximum temperature of the plasma je contacting the skin surface is $38 \mathrm{C}$. The physical effects of plasma generated by this device are well with in a safe range for medical applications. The device is portable, allowing treatments to take place in a dental chair.

With regard to the study protocol CAP was delivered in cycles of 3 single treatments within 1 week, followed by an intermittence of 1 week without CAP exposure CAP treatment proceeded by repeatedly scanning the area of the tumor with the visible plasma effluent for $1 \mathrm{~min} / \mathrm{cm}^{2}$ from a distance of $8 \mathrm{~mm}$ vertically from naturally moist tissue. Technical compliance with the study protocol was difficult in rugged and fissured ulcerations. Total treatment time increase to more than $30 \mathrm{~min}$ for patients with large ulcerations exceeding 30 square centimeters.

Tumor development was evaluated by calculating the total area of the tumor ulceration under treatment monthly and comparing the actual size with the starting size. Progressive disease means obviously increasing area of tumor surface. No response means there was no change of size of the cancer ukeration following CAP. Partial remission means reduction of tumor area.

\subsection{Outcame parameters}

As parameters of clinical outcome were documented (i) the survival time of the patients from the beginning of CAP treatment, (ii) the patients' reports concerning effects on contamination, tumar growth, need of pain medication, side effects and benefit of palliation in tems of quality of life, (iii) shrinking or growing of the tumor area under treatment, calculated and documented as difference $(+/-\%)$ to the baseline (central 0-line).

Table 1

Padents enrd lat.

\begin{tabular}{|c|c|}
\hline $\mathrm{HI}$ & 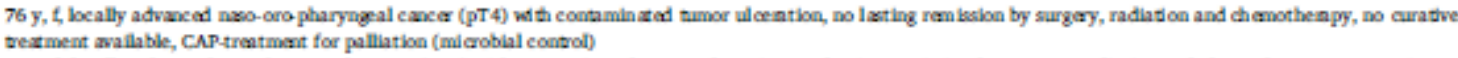 \\
\hline $\mathrm{Hz}$ & 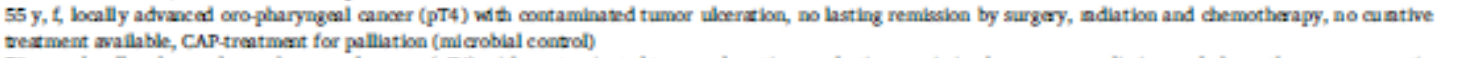 \\
\hline $\mathrm{HB}$ & 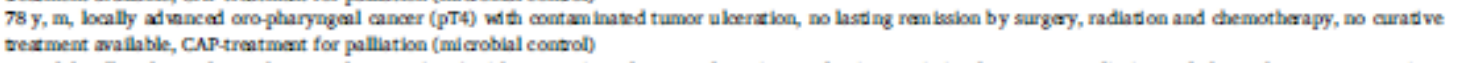 \\
\hline H4 & 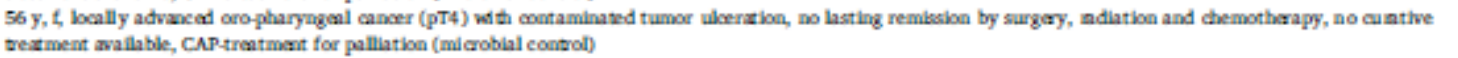 \\
\hline HS & 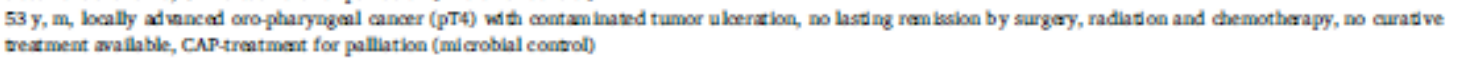 \\
\hline HS & 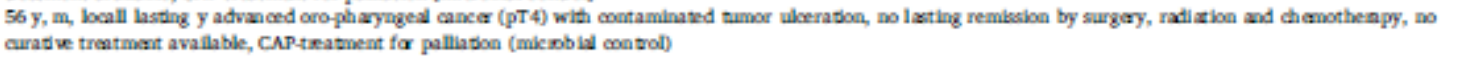 \\
\hline
\end{tabular}




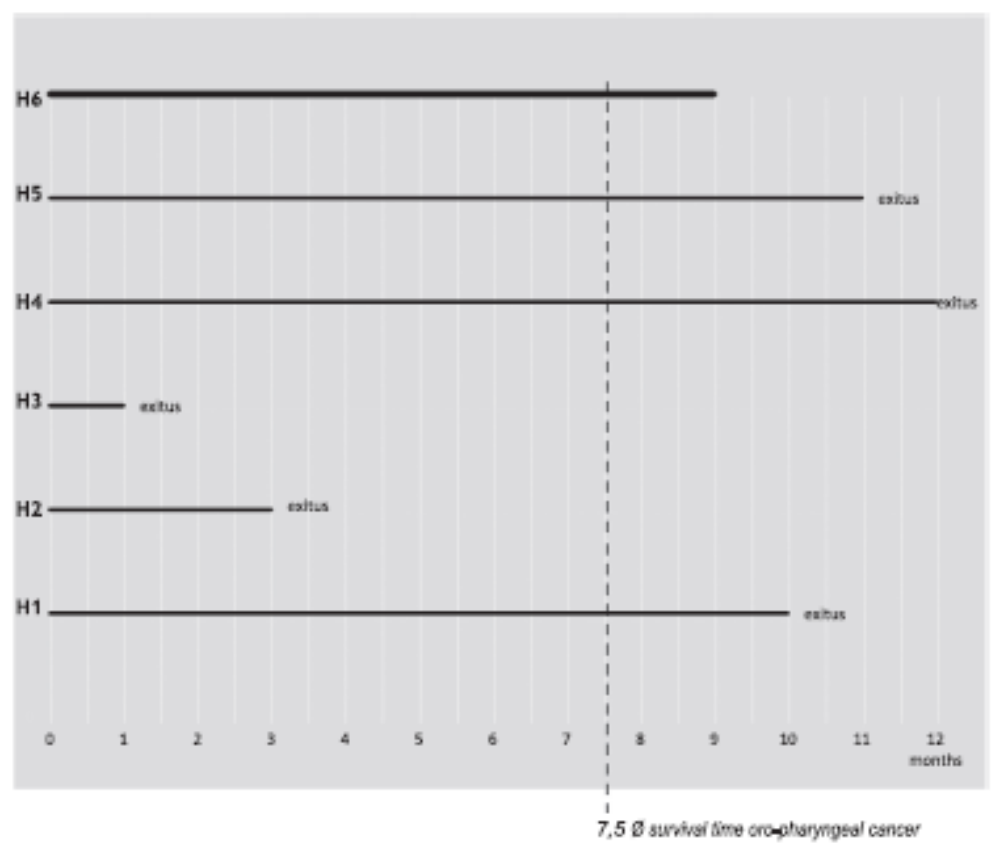

For laboratory investigations, $\mathrm{t}$ issue biopsies of the tumor site were taken and embedded in $\mathrm{OCT}^{\mathrm{N}}$, and $5 \mu \mathrm{m}$ thin cryo-sections (Leica, Gemany) were generated. To detect myeloid cells, fluorescently labeled anti-CD11b monoclonal antibodies (BioLegend, UK) were incubated on the tissue for $1 \mathrm{~h}$ at room temperature, and images were acquired using confocal laser scanning microscopy (Leica). Apoptotic cells were detected by TUNEL - assay employing in situ death detection kit (Roche, Gemany). Proliferating cells were visualized staining with a primary antibody to Ki67 (DAKO, Gemany) followed by an Alexa 594 labeled secondary antibody incubation (Life Technologies, USA). Nuclei counterstaining was achieved using DAPI (4',6-Diamidin-2-pheny lind ). Images were captured on an AxioOberver Z.1 microscope (Zeiss, Germany).

\section{Results}

\subsection{Servival time}

5 of the patients passed away between 1 month and 12 months of CAP-treatment. One patient is still under control and receiving treatment by now for more than 9 months (Fig 1). This result corresponds to expectations: With regard to the very limited literature available, the median survival time of patients with advanced cancer of oropharynx just under palliative treatment amounts to 7.5 months [6].

\subsection{Clinical results}

Table 2 is demonstrating the individual benefit of CAP treatment from the clinical point of view. Five of six patients were enjoying a reduction of odor as obvious effect of decontamination. Four of six patients presented with less demand of pain medication under CAP treatment. There were no deaths related to the application $\alpha$ CAP. There were no side effects in two patients, four patients complained of fatigue and dry mouth like symptoms. We attributed these symptoms resulted from the long lasting CAP application in the treatment of largearea tumor and the airflow of the plasma jet. Four of the patients considered CAP treatment as a noticeable palliation in terms of quality of life, in particular fatigue, nausea, vomiting, social function, emotionality and cognitive functions. The individual appreciation corresponds with the individual outcome conceming tumor growth. Viewed from the other side, the two patients with no obvious palliation were suffering from no effect on their demand of pain medication as well, some at least mild side effects, in one case no reduction of odor and, causing a lot of distress, no noticeable effect on tumor growth. In one patient CAP treatment failed in every category and the patient died after one month.

\subsection{Thanor developmert}

Six curves are following the individual courses of tumor surface size development of the six patients (Fig. 2). Patient H3 was suffering from a fast growing carcinoma that increased its size in 1 month by $50 \%$, and

Table 2

dinioal aperts of treatment effect.

\begin{tabular}{|c|c|c|c|c|c|}
\hline & Fffext on contaminarion & Effect on pain medicabon & Side effects & Palliation & Fffect on tumor growth \\
\hline н1 & Reduetion of odor & No & Pain, achawiton & No & No responose \\
\hline н 2 & Reduetion of odor & Less demand & Frhavison, (bleading), slabathen, dry mouth & Rdid & Progreasive dbense \\
\hline н3 & No wedueton & No & Fidema of the neck, (bleodling), dry mouth & - & Progresative dismse \\
\hline H 4 & Reduetson of odor & Less demand & No & Rdild & Progresedve disense \\
\hline H5 & Reduetson of odor & Less demand & $(\mathrm{p}$ ana $)$ & Relid & Partid rem betion \\
\hline н6 & Reduetion of odor & Less demand & No & Relid & Partdal rembetion \\
\hline
\end{tabular}




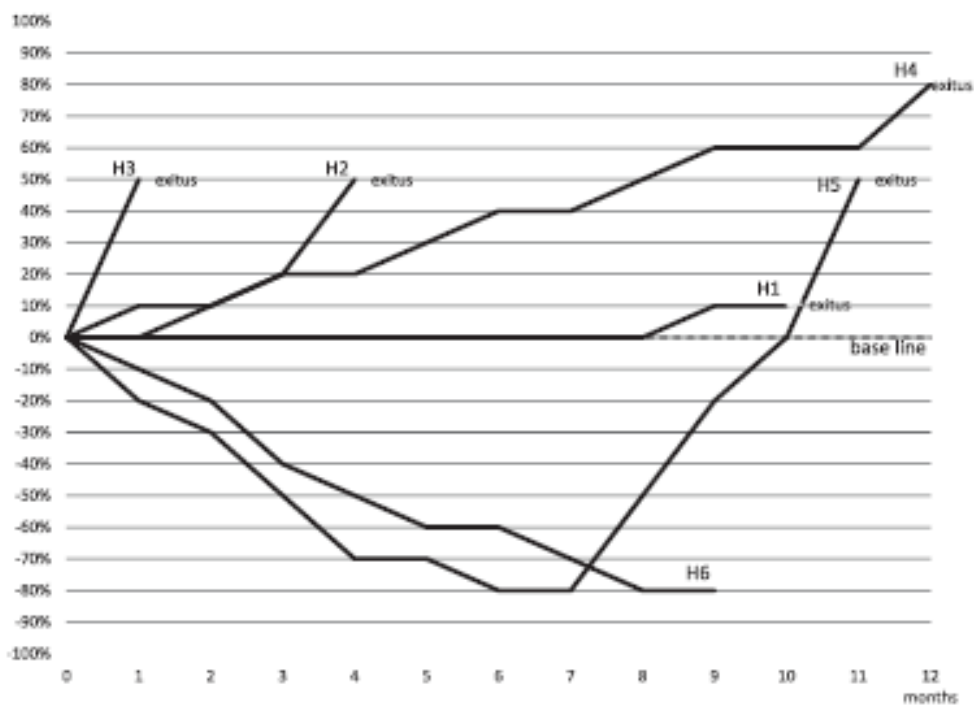

he passed away after just one cycle of CAP treatment very soon. The tumor of patient $\mathrm{H}_{2}$ was responding to CAP treatment in tems of slower growth at the beginning, however between month 3 and 4 and independent from steady treatment the speed of tumor growth became the same as in patient H3. Patient $\mathrm{H} 4$ was suffering from a tumor that was not as fast growing. However, there was never a partial remission to be documented. At the time of exitus letalis following 12 months of increasingly unsteady CAP treatment the tumor had expanded by $80 \%$. Patient $\mathrm{H} 1$ is presenting a tumor staying at the same size under CAP treatment for many months. She considered this as an encouraging course of cancer. How ever, when the tumor started to slowly grow after 8 month, the patient gave up and died.

Patient $\mathrm{H} 5$ experienced a strong response to the treatment for about 7 month and he witnessed $80 \%$ reduction of tumor surface (Fig. 3). However, tumor shrinkage did not reach total remission of $100 \%$ and the tumar started growing immediately with the same velocity as in patients $\mathrm{H} 3$ and $\mathrm{H} 2$, cutting the base line after 10 month and ending with exitus letalis shortly after. Patient 155 non-complaint with the rigid treatment protocol. Patient $\mathrm{H} 6$ is enjoying almost the same speed of tumor reduction as patient $\mathrm{H} 5$ for many months, and the shrinkage is continuous. He is still under CAP treatment aiming for $100 \%$ reduction that means total remission.

From a clinical point of view, it is important to pick the winners when considering CAP for tumor treatment more than palliation. From a scientific point of view patient $\mathrm{H} 5$ is most interesting because he started as a winner and then for no reason known became failing. The question as to why tumor remission for 7 month tumed suddenly to tumor progression whilestill underconstant unmodified CAP treatment has to be further investigated.

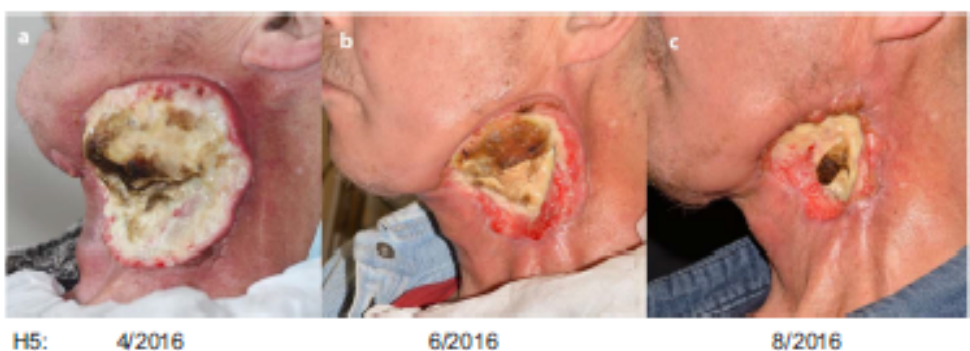

\subsection{The case of patient $\mathrm{H}^{5}$}

In February 2015, a 51-year-old Caucasian male patient presented with a well-differentiated squamous cell carcinoma of the oropharynx. The patient's medical history was significant for long-term tobacco addiction of more than 25 years. The patient underwent curatively intended tumor resection and neck dissection on both sides. The tumor was found to be AJCC stage II (pT2 pNO cM0 pL0 pVo p R0 G1).

In June 2015, CT-scan indicated a large contrast en hancing mass in contact with the extemal left carotid artery and operative findings revealed tumor tissue infiltrating the vascular wall of the external carotid, which prevented Ro (full resection). The tumor recurrence was classified as large lymph node metastasis of a well to moderately differentiated squamous cell carcinoma at $\mathrm{AJ} \propto \mathrm{C}$ stage $\mathrm{IVb}$ (pT2 pN2c cM0 pL1 pV1 pR2 G2). Between July and August 2015 the patient underwent palliative radiotherapy with a daily dosage of $2 \mathrm{~Gy}$ up to a total radiation dosage $\alpha 66.0$ Gy and 2 cycles of cisplatin chemotherapy.

In October 2015, the tumor was characterized by an extended bacterially contaminated ukeration (Fig, 3a). Due to the vulnerability of the underlying carotid artery, wound care was difficult. In January 2016 patient H5 was enrolled into the study and a supportively intended palliative cancer treatment started, applying CAP according to the trial protocol.

\subsection{Clinical response}

Efficacy against pathogens: Within the plasma treated zones infected necrotic tumor appears to becleaned of cell detritus and bacteria (Fig. 3c). Microbiological examination reveals a reduction of bacterial

Fig . 3. Clini cal course of prient $\mathrm{HS}$ 


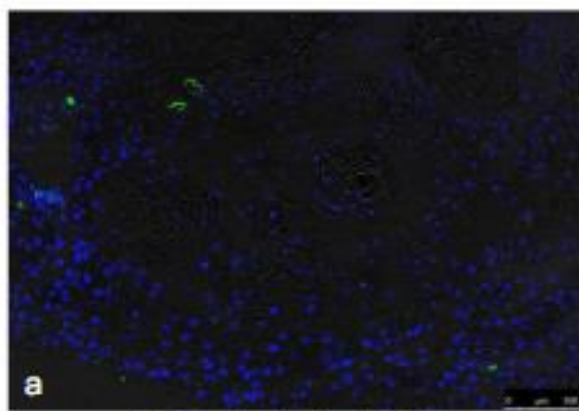

H5: Decontamination $(\mathrm{CD} 11 \mathrm{~b}+)$

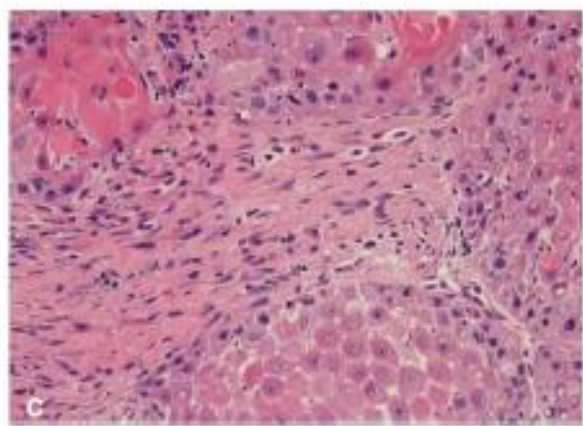

H5: Desmoplasie (HE)

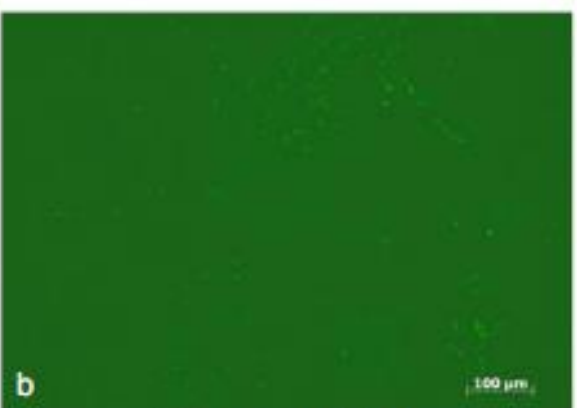

H5: Apoptosis (TUNEL)

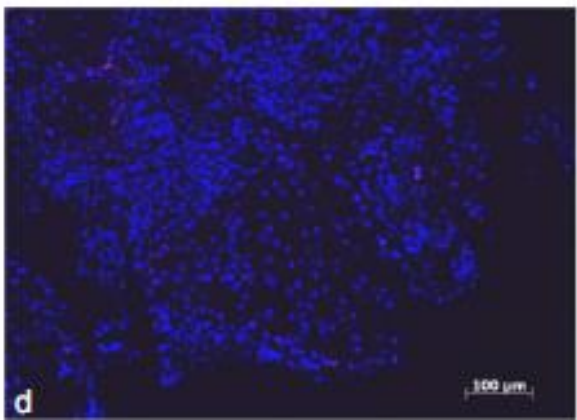

H5: Proliferation (Ki67)

Fig. 4. Bbopay resuls of perient H5.

colonization, significantly anaerobic bacteria like bacteroides spp. which leads to decrease of bacterial decomposition products and wound odor, too. Decrease of local and perifocal inflammation resulted in significant reduction of vulnerability and wound algesia.

Tumor response: A significant reduction of wound area is obvious (Fig. 3a-c) with the ulcerated tumor area being reduced to one-quarter of its original size. Margins and center of the wound are sclerosed and calloused. A physiological fibrin coating costs the wound bed. Despite infiltrating of the vascular wall of the underlying external carotid, carotid artery is still intact and sonographic investigation reveals regular blood flow without thrombosis.

\subsection{Bicpsy resuls}

Incisional biopsies were performed to verify changes at the cellula level. Similar to healthy skin, immunofluorescence staining of CD11b cells in the plasmatreated tumor reveals an only minor presence of myeloid cells whereas high numbers of $\mathrm{CD}_{11} \mathrm{~b}^{+}$cells were found in tisue sections of other patients that did not receive physical plasma (Fig. 4a). TUNEL analysis demonstrated a moderate amount of apoptotic tumor celk (Fig. 4b). Furthemore, a desmoplastic reaction of the conjunctive tissue by an increased production of extracellular matrix is histologically visible (Fig 4c), whereas proliferating celk remain very sparse (Fig. 4d)

In summary, CAP induced tumor reduction and significant improvement in tumor decontamination and tumor mass (Fig, 3). The main plasma effect seems to be a combination of a superficial cancer cell interaction, apoptosis and a deep desmoplastic kind of a scar for mation. The tumor remission by CAP appears to be promising, however it turned out, that this remission has not been lasting.

\section{Discussion}

The number of clinical reparts conceming CAP treatment of cancer areas is small, and so is the understanding of what might explain the clinical anticancer effect in this case and maybe the later bos in contrast. There are especially three specific approaches as food for discussion to understand at least the mechanism of action in cancer.

\subsection{The role of myeloid cells}

In healthy skin, myeloid celk such as tissue-resident macrophages usually reside around epidemal ridges in the papillary layer of the demis [7], and accordingly $\mathrm{CD} 11 \mathrm{~b}^{+}$cells have been detected in this region. Like in other cancer entities such as breast cancer [8], prostate cancer [9], or endometrial cancer [10], large numbers of tumor-associated macrophages are associated with a poor prognosis also in head and neck cancer [11]. Interestingly, tumor tissue of the patients that had received frequent plasma treated was almost devoid of myeloid cells, which is generally associated with a good prognosis in progressive head and neck cancer [12]. It can only be speculated whether this was either a direct consequence of the plasma treatment or a secondary effect due to a plasma-assisted decrease in bacterial burden of the infected cancer tisue.

\subsection{The ROS/RNS model of understanding the clinical effect}

It is intriguing to see that CAP had a profound effect both on bacterial and on tumor growth. Assuming that ROS/RNS (reactive oxygen species/reactive nitrogen species) contained in CAP were the most likely responsible effector molecules during therapy, the question may be raised whether the species that caused the ant ibacterial effect were the same as those that caused the antitumor effect. In a recent study, Wu and coworkers have demonstrated that the dominating 
antibacterial effect of CAP was due to singlet oxygen $\left({ }^{1} \mathrm{O}_{2}\right)$ and that hydraxyl radicals contributed to a minor degree [13]. Singlet oxygen, an excited state of molecular oxygen, is not only contained in CAP, but in addition, it can be generated from certain CAP components [14].

Importantly, model experiments with a defined source of singlet oxygen showed that extracellular application of singlet oxygen had a strong and selective apoptosisinducing effect on tumor celk, but did not affect nonmalignant cells. In contrast, intracellular generation of singlet oxygen caused nonselective cell death in both cell types. The detailed analysis of this process showed that extracellular singlet oxygen inactivated membraneassociated catalase, which is characteristic $\alpha$ tumor cells [15]. In add ition, tumor cells show sustained activity of membrane-associated NADPH oxidase 1 that generates extracellular superoxide anions These are required for maintaining proliferation and the malignant state of tumor cells, but also drive two intercellular ROS/ RNS-dependent apoptosis-inducing signaling pathways. Membraneas sociated catalase of tumor celk interferes with intercellular apoptosis. inducing signaling. Local inactivation of membrane-associated catalase prevents decomposition of $\mathrm{H}_{2} \mathrm{O}_{2}$ and peroxynitrite. As a result, these species interact in a complex reaction chain and generate secondary singlet oxygen that inactivates additional catalase molecules. This attoamplification of singlet oxygen generation, originally triggered by exogenously applied singlet oxygen, finally depletes the tumor cells of their protective membrane-associated catalase and causes their selective death through ROS/RNS signaling-mediated apoptosis induction.

In a recent analysis, these data obtained from model experiments were compared to data related to the potential effects of other CAPderived ROS/RNS. This allowed to conclude that singlet oxygen from CAP seemed to be the most likely primary candidate to explain selective apoptosis induction in tumor cells in vitro and tumors in vivo. Therefore, if the data related to the connection between NOX1 and catalase in tumors can be trandated to human tumors in a clinical situation, it seems reasonable to consider that the beneficial effects of CAP for the patient presented in this manuscript might be due to the same biochemical and cell biological scenario, dependent on an initial singlet oxygen-dependent step.

A rigid analysis is required that is suitable to determine whether application of CAP on tumor celk can be fully explained by singlet oxygen, in analogy to the model experiments described earlier. This analysis will not be trivial, as it will require to differentiate between the effects of CAP-derived singlet oxygen, singlet oxygen generated by CAP components, singlet oxygen potentially generated in plasma activated medium [16] and secondary singlet oxygen generated by targeted tumor cells

If the anticipated scenario can be proven to be true, these findings should open ways to optimize CAP treatment of tumors through modulation of the CAP components, e. g. favoring a relatively high content of singlet oxygen. Based on the high standard of the physics of CAP, such modulations seem to be feasible in due course [17].

However, the experimental elucidation of the primary CAP-derived species that triggers the onset of the selective cascade of death inducing effects in tumor cells should not prevent us from reflecting on co-application of other species during treatment. For example, though singlet oxygen is discussed as primary antitumor agent in CAP in a recent analysis [14], and NO at moderate concentrations was found not to have the potential for effective initial interaction with the protective system of tumor cells against ROS/RNS signaling, the application of NO in parallel to singlet oxygen might enhance the steps that follow catalase inactivation by singlet oxygen. These steps are generation of secondary singlet oxygen through the interaction between $\mathrm{H}_{2} \mathrm{O}_{2}$ and peroxynitrite as well as apoptosis induction through formation of peroxynitrous acid. More examples of such useful and enhancing interactions have already been experimentally estab lished.

If singlet oxygen inactivation of tumor cell protected catalase can be shown to be indeed the driving force for selective tumor therapy in vivo, the established knowledge on the optimization of singlet oxygen- dependent apoptosis induction in tumor cells should allow us to define regimens that utilize mechanism-based synergy effects. In this way, the required doses for CAP might be lowered. This mechanism then might open the way for effective treatment of tumors through micro-invasive CAP generators.

A concerted scientific action, based on work in vitro and animal models in vivo, focusing on future therapeutic applications to patients, is therefore required. The intellectual and technical basis required to achieve this goal is available and should be further activated and encouraged.

\subsection{The inmunogenic cell death modd of ancer treatment}

Tumors employ several immunosuppressive strategies to escape the body's nomal immune surveillance and elimination. Recent advances in our understanding of mechanisms involved in tumor immunity have led to increased efforts in development of immunotherapeutics for cancer [17]. One such modality relies on exposure of new antigens on tumor cells via the immunogenic cell death (ID) pathway [18,19]. Since several steps in this pathway are ROS dependent, plasma is a viable candidate for this type of oncoimmunotherapy [20].

As such, plasma effects are largely mediated by ROS, but it is the concentration of ROS that influences the kind of biological effects achieved [21]. Rapid delivery of large amounts of toxic species cause: cells to die. In context of cancer treatment, th is would result in a quick, ablative debulking of tumor mass, as is seen in the patient case study presented here. The smaller tumor may then become more manageable by the compromised immune system. In addition, plasma decontamination of the exulceration further reduces the burden on the already drained immune system to combat multiple, different assaults A simultaneous reduction in the immunosuppressive cell population in the tumor microenvironment can be an additional beneficial outcome. It is believed that once dendritic cells (DC) are committed, their immunosuppressive nature cannot be reversed. Hence, their elimination may be the only option and plasma at these ablative regimes can do that, as shown in this case study. Together, the debulking of tumors, decontamination of open ukers and removal of immunosuppressive cells provides symptomatic relief to the patient and perhaps increased life expectancy.

Another method plasma may be employed for active immunotherapy of cancer is treatment in the ICD-causing regime. Softer than the ablative plasma regime, it operates by inducing endoplasmic stress pathways that result in generation of several molecules called damage associated molecular patterns (DAMP) that include ATP, calreticulin (CRT), HMGB1, HSP70, HSP90 etc. [18,22,23], cells follow a canonical pathway where they release ATP as a "find me" signal for antigen presenting cells (APC) immediately after plasma exposure $[24,25]$. This signal brings about the recruitment of APCs like DCs and macrophages to the bcal area [26]. Soon after, CRT is extemalized on the membrane of plasma-stressed cells [24] to act as the "eat me" signal for the recruited APCs to phagocytose and destroy these cells [23]. The tumor cell laden APCs travel to draining lymph nodes to present the neoantigens exposed during this process to cognate T-celk. The tumor specific T-cells thus generated travel to the tumors (plasma treated or untreated, metastatic masses) and destroy them through production of cytotoxic molecules like TNF $\alpha[27]$. Hence, tumors are dest royed by the highly selective natural defense pathways of the body. Another ad. vantage of this ICD-inducing plasma regime is that it actively recruits and stimulates APCs instead of destroying them $[24,28]$. Therefore, we achieve tumor debulking through concomitant stimulation of immune responses.

Cancer is a complex disease and it is unlikely that a single treatment modality will successfully cure patients. Perhaps, a combination therapy with plasma - first plasma hit in ablative regimes followed by ICD-inducing regime - would be the ideal way to treat tumors with plasma Alternatively, better optimization of plasma systems may 
achieve both outcomes. In a recently completed small clinical trial, we show that actinic keratosis lesions resolved with a single nanosecond pulsed dielectric barrier discharge (DBD) plasma treatment. This system is adaptable for treatment of different surface areas by altering electrode geometry. A few of these patients reported overall clearing of skin and reduced incidence of new lesions at the 4-month follow-up. None of the patients reported immediate or late adverse effects.

While these small studies highlight the promise that plasma has in the field of oncoimmunotherapy, further exploration of mechanisms, both plasma and biological, are required to achieve consistently reproducible results [29-31].

\subsection{Reflections on nonsustainable tumor reqponse}

In patien $\mathrm{H} 5$, the tumor remission by CAP appeared to be promising for several months What might be the reason why it tumed out that this remission has not been sustainable?

The los of effectiveness under long-term plasma treatment of cancer tissue opens questions about plasma application and protocol. At first, it must be considered that the treated area is morphologically and chemically changing over the time, from activated surrounding to more nomal tissues which are less humid and bacteriologically cleaner. This implied that over the time there is a modification of the tumor microenvironment and of the tissue conductivity that can greatly affect the plasma composition itself and the plasma induced processes mentioned in the discussion. It is known from literature [32-34] that for any type of plasma jet, the nature of the target, and specially its conductivity, influences the production (not only concentrations but also production zones in the jet) of reactive species, such as $\mathrm{NO}, \mathrm{OH}, \mathrm{H}_{2} \mathrm{O}_{2}$ and others, which play a direct role in the observed results. Concentration can increase by orders of magnitude and zone of production can change from plasma column volume to near target surface when the target characteristics change from near insulator to highly conductive material. Therefore, it can be expected that changes will occur in the ROS/RNS production between the start of the treatment and the treatment after few months due to tissue modifications, in the present case most probably leading to a decrease in the reactive species production. This will also affect the potential diffusion of species through the tissue upper layers, then change the cell signaling pathways and thus the triggering of the immune system that has been evoked earlier in this paper. This may also affect the potential role of the plasma jet generated electric field since penetration is also clearly related to the tissue characteristics and can play on local cell permeabilization important for the exchanges through the cell membranes. Other possible changes occurring during the overall treatment are the tissue oxygenation and bcal blood flow that have been shown to vary under plasma action [35-37]. This last mechanism can consequently affect all other processes previously mentioned in this paragraph in a way that cannot be determined yet. It clearly appears that tissue modifications all along the treatment may play a deleterious role that reduces plasma efficacy and then partly explains the non-sustainable remission. All of this would imply to pay extreme attention to possible modifications of the plasma characteristics during treatment over months, which is not easy to realize in real conditions. In a first step, it would be nice to add simple spectroscopic measurements (realized with the use of a fiber optic connected to a compact spectrometer) in the plasma wone near the treated surface at different stages $\boldsymbol{\alpha}$ the patient treatment to follow probable plasma emission modifications leading to a qualitative evaluation of changes in the excited radical species production. This will not lead to a direct evaluation of the treatment efficacy, but will potentially help to modify the treatment protocol by varying single fraction treatment time accordingly. In the future, in a specific study, it will be helpful to follow the treated tissue modifications to go deeper into the comprehension of the involved mechanisms in the observed results.

\section{Conclusion}

Clinical observation indicates a relevance of CAP in cancer treatment. Cancer patients under palliation with CAP resulted in a reduction of odor as obvious effect of decontamination, and less demand of pain medication, and very mild side effects. Four of the six patients enrolled in this observation considered CAP treatment as a noticeable palliation in tems of quality of life, in particular Gatigue, social function and emotionality. Following their individual courses of tumor development, two patients were suffering from fast growing carcinoma, another two from slow or during longer periods not growing tumors and two patients enjoyed a strong response to CAP, one still persistent, the other having experienced a sudden relapse. Incisional biopsies of this tumor at the time of remission revealed minor presence of myeloid cells, a moderate amount of apoptotic tumor cells, a desmoplastic reaction of the conjunctive tissue by an increased production of extracellular matrix, whereas proliferating cells remained very sparse To explain the clinical anticancer effect, there are three approaches for understanding: (i) the role of myeloid cells, (ii) the ROS/RNS model of cellular impact and (iii) the immunogenic cell death model of cancer treatment. Reflections about why some tumors are responding very well to CAP and why some do not, and why some change their reaction under constant treatment are of outstanding clinical importance to pick the winners when considering CAP in the future for tumor treatment more than palliation.

\section{Acknowledgements}

This work could not have been completed without the support of Wolfram Kaduk and Axel Schriewer as surgeons, Anke Friedrich, Martina Bottcher and Runa Tschersche-Mondry as wound nurses and Kerst in Böttger as system consultant in the Department of Oral and Maxillofacial Surgery, Greifswald University.

\section{Conflict of interest}

The authors declare no potential conflicts of interest. The CAP medical device is in clinical just due to approval and supplied by the manufacture without financial obligations

\section{References}

[1] I Schlogel, J. Kooriter, v. Borhammer, Plasma in eancer treatment, din. Plasma Med. 1 (2013) 2-7.

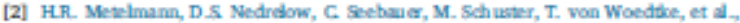
Head and neck cancer treatment and physioal plama, din. Plexma Med. 3 (2015) $17-23$

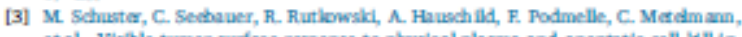
et al, Varbic tumor surface responee to physical plasma and apoptotic oell is ill in head and neck caner, J. Cranio Marill Surg. 44 (2016) 1445-1452

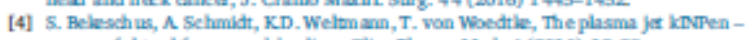
a ponserful tool for wound helling, Clin. Plasma Med. 4 (2016) 19-28.

[5] K.D. Wd tmann, E. Kindel, R. Branden burg, C Meyer, R. Busejahn, C. Willee, et d. Amochheric presesure plama jet for medical therapy: plasma paramesurs and rial

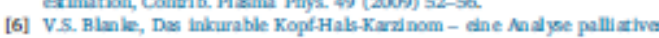
Therapieoptonen (Inagizul Diesertation), Gotringen University, 2011.

(7) F.Y. 1.in, J.W. Polllard, Tumor-aseodated macrophages press the anglogenie sud th

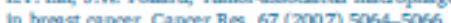

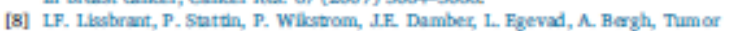
asoelated macrophages in hum an prostate caner, red ation to dinicopath dogloal

[9] S. Ohno, Y. Ohno, N. Surukli, T. Kame, K. Kolloh, H. Inagnwa, a a L, Corredation of

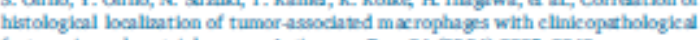
features in endometrial cancer, Antileancer Res 24 (2004) 3335-3342.

[10] S. Koonnon glaen, The tumor microenvironment contribution to devd opment, gronth, imvaion and meraxass of head and neck squamous edl cardnomas, J. Cance 4 (2013) $66-83$

[11] P. Balermpas, F. Rodel, R. L.lber, I Oppermann, I. Whgenblax, S. Chanaat, a d. Head and neck eancer relapoe atter chemoratiotherapy correlates with ofl $63+$ macrophages in primary nimour and od $11 \mathrm{~b}+$ myeloid colls in recurrences, Brit. J. Cance 111 (2014) 1509-1518.

[12] D.R. Graves, The emerging role of mactive anyen and nibrogen spedes in redor 
biology and some implications for plasma applicatons to medicine and biology, I Phys. D. Appl. Phys. 45 (2012) 263001.

[13] H. Wu, P. Sun, H. Feng, H. Thou, R. Wang, Y. Liang a al, Reuctive arygen species

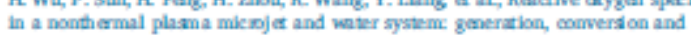
contributions to bacteria inadivarion-an andysia by electron spin mesonanse spee.

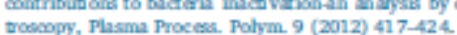

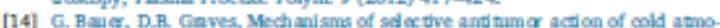
spherie plama-derived rexet ve orygen and nitrogen spedes, Pl arma Proceses Polym. 13 (2016) 1157-1178,

[15] M. Rierhmiller, N. Burger, C. Rever, Singlet arygen trentment of tumar edils tilg. gers extracellular singlet orygen genention, caralas inadrintion and renctivation of intercellular apoptockis-inducing signalling, Redox Bial. 6 (2015) 157-168.

[16] A. Schmitt-Bleker, R. Baneemer, S. Reuter, K.D. Welten man, How to produce an

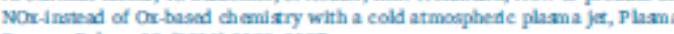
Procese. Polym. 13 (2016) 1120-1127.

[17] I. Mellman, G. Coulkos, G. Danoff, Canoer immunotherapy comes of age, Nature $490(2011) 490-489$.

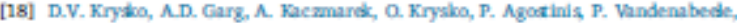
Imm unogenie cell deuth and DMMPs in cancer therapy, Nat. Rev. Caned 12 (2012) $860-875$.

[19] G. Kroemer, 1. Gallumzi, O. Kepp, 1. Zitwogel, Immunogenie edl de:th in cances therapg, Anmu. Re. Immunal 31 (2013) $51-72$

[20] V. Miller, A. Lin, A. Fridman, Why target immune cells for plasma treatnent of cancer, Plama Chem. Plasma Procesa. 36 (2015) 259-268

[21] F.H. Sarsour, M.K. Kumar, L. Chaudhuri, M.. Kalen, P.C Goenenmi, Redor control

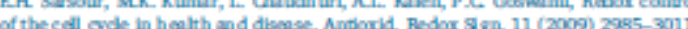

[22] L. Galluari, A. Bugue, O. Kepp, I. Zitvogel, G. Koemer G, Immunogenie cell deat in cancer and infertous d bonas, Nat. Res. Immunol. 17 (2017) $97-111$.

[23] M. Obeld, A. Tesniere, F Chiringhelli, G.M. Fimia, I. Apetho, J1. Pedert nie, et al, Calredeulla apoerure dictates the immunogenidity of eancer efll denth, Nat Med. $13(2007)$ 54-61.

[24] A. Lin, B. Truang, A Pappas, 1. Wrifides, A. Oubarri, S. Chen, ef al, Uniform ma.

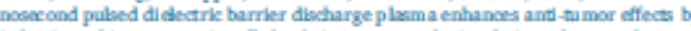
induetion of immunogeric eell dezth in tumors and stimulation of macrophages, Plasma Procesc. Polym. 12 (2015) 139213-139299.

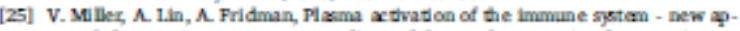

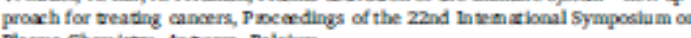
Plasma Chem broy, Nanerp, Belglum.

[26] A. In Sals, D. Fermari, F. Di Virgllba, M. Idako, I Norguer, G. Girabmoni, Nerting and tuning the immune respone by ertracellular mudeotdes, 1 leuboc, Biol. 73 (2003) $339-343$

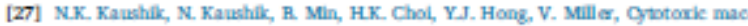

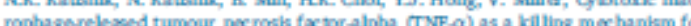

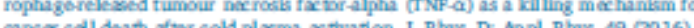
os4001.

[28] V. Miller, A. 1in, G. Fridman, D. Dobrynin, ᄉ. Fridm m, Plasma stimulation of mi gration of macrophages, P lama Procese. Polym. 11 (2014) $1193-1197$.

[29] $\mathrm{A}$. Schm idt S. Bedueschus, T. von Woedtie, S. Hason, Cell migraton and adhesion of a human melanoma cell line is decreased by cold plasma treatment, Clin. Plasma 3 (2015) 24-31.

[30] H. Jablonowskil, I. von Wontike, Research on plasma medicine-redevant plasma liquld imeractions what happened in the part flve years? din. Plama a Med 3 (2015) $42-52$

[31] F. Otaumi, H. Kaflyama, K. Nobamura, H. Tanaka, M. Hori, F. Kilkawa, et al, Fffece of indireet nonegull ibrium atmospheric presure plasma on ant-prollferative ae. tivity agin $x$ chromic chemo-vesitant ovarian cancer cells in vitro and in vivo, Plos One 8 (2013) es1576.

[32] K. Unabe, T. Morita, K. Taehibana, B.N. Ganguly, lmestigation of divehane mecharians in hellum plasma jet at atmospheric pressure by laser spex troecopic mesurements, I. Phiys. D Appil. Phys. 43 (2010) 95201.

[33] S. Yonemari, R. Ono, Flux of OH and $\mathrm{O}$ radieals onto a surhex by an atmoghterie presaure hellum plasma ja messured by hase-induced fluaresoenes, J. Phys. D Appl. Phys. 47 (2014) 125401.

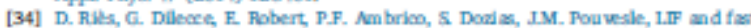
imaging plama jet charncteriaation relovant for NTP biomedical applicartiona, I. Pliyg. D Appl. Plyys. 47 (2014) 275401.

[35] G. Collet F. Fobert A. 1enoil, M. Vandrmme, T. Darny, S. Dowias, C. Kieda, IM. Pouvesle, Plama jas-dnduoed thesue arygenation potentilities for nos ther.

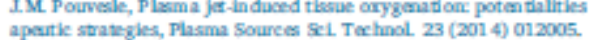

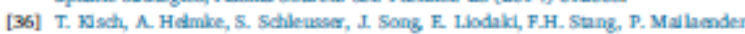
R. Kremer, Improvenent of cut maneous micocirculation by eald atmospherie plasma (CAP): results of a control lind, proespective cahort staidy, Micioviac. Rea. 10 (2016) $55-62$

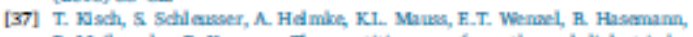
P. Mallaender, R. Knemer, The reperitive we of non thermal dielectric barrie: diveharge plasma beosts cutaneous mi crodreulatory effects, Mecwvasc. Res. 106 (2016) 8-13 